\title{
Modelling of Dross Height in Plasma Jet Cutting Process of Aluminium Alloy 5083 Using Fuzzy Logic Technique
}

\author{
Ivan PEKO*, Bogdan NEDIĆ, Marko DUNĐER, Ivan SAMARDŽIĆ
}

\begin{abstract}
Dross height is an important cut quality characteristic in plasma jet cutting process. It can be defined as molten metal blown from the cutting zone and localized on the bottom of the metal sheet. In each plasma jet cutting process, it is important to obtain dross free cuts. Aluminium is as material very present in shipbuilding and metal industry and because of that very usually cut by plasma jet. Because of high heat and electrical conductivity of aluminium, plasma jet cutting is followed by insecurity about process parameters settings that lead to optimal cut quality characteristics. The aim of this paper is to develop a fuzzy logic model that predicts the influence of variable process parameters on dross height in plasma jet cutting of aluminium alloy 5083. Experiments were performed according to Taguchi $L_{27}$ orthogonal array by varying cutting speed, arc current and cutting height as input process parameters. Fuzzy logic model was defined using Mamdani inference system. This model was used to investigate effects of variable process parameters on dross height response. In order to analyse interaction effects of plasma jet cutting process parameters on dross formation 3D surface and contour plots were generated. The analysis revealed that the cutting speed has the most significant effect followed by arc current and cutting height. Obtained results of this research indicate that artificial intelligence technique, fuzzy logic, can be effectively used for modelling and prediction of dross formation in plasma jet cutting process of aluminium alloy.
\end{abstract}

Keywords: aluminium alloy; dross height; fuzzy logic; modelling; plasma jet cutting

\section{INTRODUCTION}

Plasma jet cutting is nonconventional manufacturing process very present in shipbuilding and metal processing industry. In this process the energy of highly ionized gas is used for cutting different types of materials such as: mild steel, stainless steel, aluminium, copper, etc. Plasma jet contains a very high amount of energy and because of that it can be used for cutting materials at various thicknesses up to $150 \mathrm{~mm}$. The result of plasma jet cutting process is a cut quality that is defined by different characteristics such as: kerf width, bevel angle, surface roughness, dross height, productivity etc. These characteristics are mostly influenced by process parameters settings defined by technologists. They manually define the process parameters' values in order to achieve optimal cut quality. Generally, process parameters differently affect cut quality characteristics. It is usually a case that the parameters' settings at the same time improve one and make worse another cut quality characteristic. Due to that many authors conducted comprehensive researches in order to describe the influence of these variable process parameters on the cut quality characteristics and to define their optimal values. These findings can be very useful in daily industrial applications of this manufacturing process.

Peko et al. [1] analyzed the influence of cutting height, cutting speed and arc current on kerf width response by plasma jet cutting of aluminium alloy 5083. They defined an artificial neural network model to predict the analyzed process response and to create parameters interactions surface plots. Developed mathematical model can be used further in optimization procedures such as genetic algorithm. Kumar Das et al. [2] conducted experimentation on steel EN 31. They analyzed the influence of gas pressure, arc current and torch height on material removal rate and surface roughness characteristics. Multi objective optimization was performed by using grey relational analysis combined with analysis of variance (ANOVA). Adalarasan et al. [3] conducted experimentations on stainless steel 304 Lby varying parameters such as air pressure, cutting speed, arc current and stand off distance. Cut quality characteristics that were analyzed were kerf width and surface roughness. In order to perform multiobjective optimization the Grey Taguchi based response surface methodology was used. Tsiolikas et al. [4] performed experimentations on carbon steel $\mathrm{St} 37$ by varying process parameters: cutting speed, standoff distance and arc voltage. Surface roughness characteristics $R_{\mathrm{a}}$ and $R_{\mathrm{z}}$ are process responses that were analyzed. Taguchi technique combined with ANOVA was used in order to define process parameter values that lead to minimal surface roughness and to quantify the significance of each process parameter on the responses. Maity et al. [5] performed optimization of kerf, chamfer, dross, surface roughness and material removal rate in plasma jet cutting of stainless steel AISI 316. Process parameters that were varied in experimentations were: feed rate, arc current, arc voltage and torch height. Multiobjective optimization was done by using response surface methodology and grey relational analysis coupled with principal component analysis. Radovanović et al. [6] defined artificial neural network model of surface roughness $R_{\mathrm{z}}$ that describes an influence of parameters: cutting current, plate thickness and cutting speed on the response. They conducted experiments on the stainless steel EN 10025. Developed artificial neural network mathematical model was validated and used to create contour plots from which optimal cutting areas were identified. Srinivasa Raju et al. [7] conducted experiments on mild steel E30 plate. They analyzed the influence of cutting current, cutting speed and cutting height on bevel angle. Analysis of means (ANOM) was used to define the process parameters values that lead to minimal bevel angle. Percentage significance of each parameter on the process response was defined by performing ANOVA. Regression model was also defined to better understand the effects of the analyzed process parameters on the bevel angle response. Pawar et al. [8] performed an optimization of kerf width and taper by using grey relational analysis approach in plasma jet cutting process of stainless steel $316 \mathrm{~L}$ at three different thicknesses 
of 4, 8 and $12 \mathrm{~mm}$. Process parameters that were varied in experimental plans were arc voltage, cutting speed and gas pressure. ANOVA was performed to define the significance of parameters on analyzed process responses. Salonitis et al. [9] used Taguchi method, combined with ANOM and ANOVA in order to define the process parameters' values that lead to minimal conicity, heat affected zone (HAZ) and surface roughness. Analyzed process parameters were: cutting speed, cutting current, cutting height and gas pressure. For each cut quality characteristic percentage significance of process parameters was defined by using ANOVA. Surface contour plots were created in order to show the influences of process parameters on the cut quality responses.

In this paper, authors conducted a research in plasma jet cutting process of aluminium alloy 5083. Process parameters that were varied in experimentations were: cutting speed, arc current and cutting height. Cut quality was analyzed in the terms of dross height characteristic. Fuzzy logic artificial intelligence technique was used to create functional relations between inputs, process parameters, and output, dross height. Developed fuzzy logic model was validated by additional experimentations. Validated fuzzy logic model was used to describe and predict the influence of variable process parameters on the dross height response and to find an optimal cutting area.

\section{EXPERIMENTAL SETUP}

All experiments were performed on aluminium sheet Al 5083, thickness $3 \mathrm{~mm}$. CNC machine that was used for experimentation was FlameCut 2513. All experiments were conducted according to Taguchi $\mathrm{L}_{27}$ experimental plan by varying three process parameters: cutting speed, arc current and cutting height on three levels. Constant parameters were: outlet nozzle diameter: 1,2 $\mathrm{mm}$ and plasma gas pressure (compressed air): 6 bar. In each experimental trial straight cut length of $80 \mathrm{~mm}$ was made. Dross height was measured by using universal optical microscope on the bottom side of the cut. Each measurement was done on three equidistant places in the middle of the cut. Mean value of all three measurements was calculated and taken as a result of single experimental trial (Fig. 1) Experimental plan and obtained results are shown in Tab. 1.

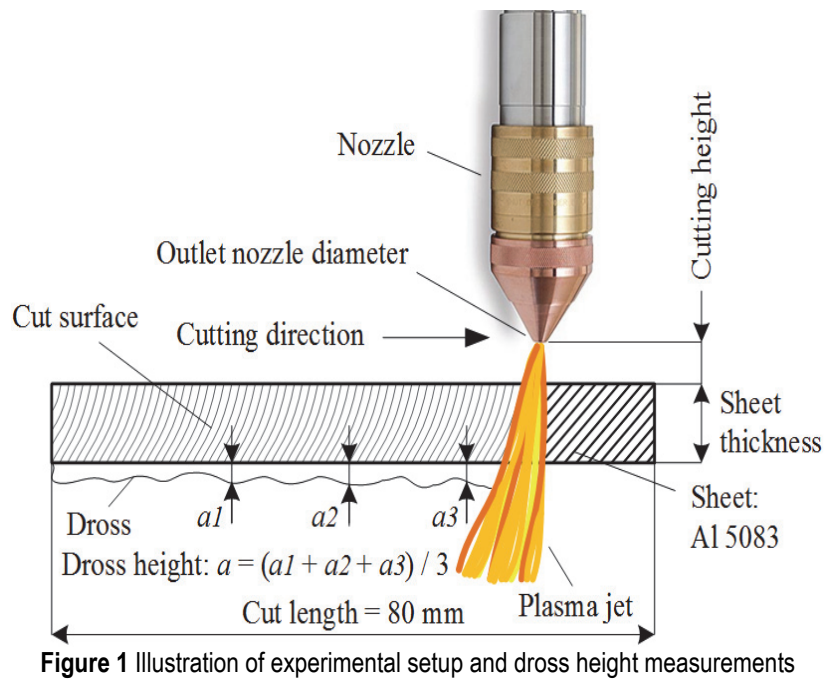

Table 1 Taguchi $\mathrm{L}_{27}$ experimental plan and results

\begin{tabular}{|c|c|c|c|c|}
\hline \multirow[b]{2}{*}{ Exp. Trial } & \multicolumn{3}{|c|}{ Process parameters } & \multirow{2}{*}{$\begin{array}{c}\text { Response } \\
\text { Dross height } \\
a / \mathrm{mm}\end{array}$} \\
\hline & $\begin{array}{l}\text { Cutting speed } \\
v / \mathrm{mm} / \mathrm{min}\end{array}$ & $\begin{array}{c}\text { Arc current } \\
I / \mathrm{A}\end{array}$ & $\begin{array}{c}\text { Cutting } \\
\text { height } H \text { / } \\
\text { mm }\end{array}$ & \\
\hline 1 & 2000 & 45 & 1 & 0,27 \\
\hline 2 & 2000 & 45 & 1,5 & 0,24 \\
\hline 3 & 2000 & 45 & 2 & 0,22 \\
\hline 4 & 2000 & 65 & 1 & 0,51 \\
\hline 5 & 2000 & 65 & 1,5 & 0,50 \\
\hline 6 & 2000 & 65 & 2 & 0,52 \\
\hline 7 & 2000 & 85 & 1 & 0,34 \\
\hline 8 & 2000 & 85 & 1,5 & 0,41 \\
\hline 9 & 2000 & 85 & 2 & 0,32 \\
\hline 10 & 4000 & 45 & 1 & 0,22 \\
\hline 11 & 4000 & 45 & 1,5 & 0,26 \\
\hline 12 & 4000 & 45 & 2 & 0,24 \\
\hline 13 & 4000 & 65 & 1 & 0,20 \\
\hline 14 & 4000 & 65 & 1,5 & 0,17 \\
\hline 15 & 4000 & 65 & 2 & 0,13 \\
\hline 16 & 4000 & 85 & 1 & 0,18 \\
\hline 17 & 4000 & 85 & 1,5 & 0,21 \\
\hline 18 & 4000 & 85 & 2 & 0,19 \\
\hline 19 & 6000 & 45 & 1 & 0,68 \\
\hline 20 & 6000 & 45 & 1,5 & 0,75 \\
\hline 21 & 6000 & 45 & 2 & 0,28 \\
\hline 22 & 6000 & 65 & 1 & 0,27 \\
\hline 23 & 6000 & 65 & 1,5 & 0,27 \\
\hline 24 & 6000 & 65 & 2 & 0,23 \\
\hline 25 & 6000 & 85 & 1 & 0,17 \\
\hline 26 & 6000 & 85 & 1,5 & 0,14 \\
\hline 27 & 6000 & 85 & 2 & 0,15 \\
\hline
\end{tabular}

In Tab. 2 are given examples of dross formation that appeared on the aluminium sheet bottom depending on different input process parameters values.

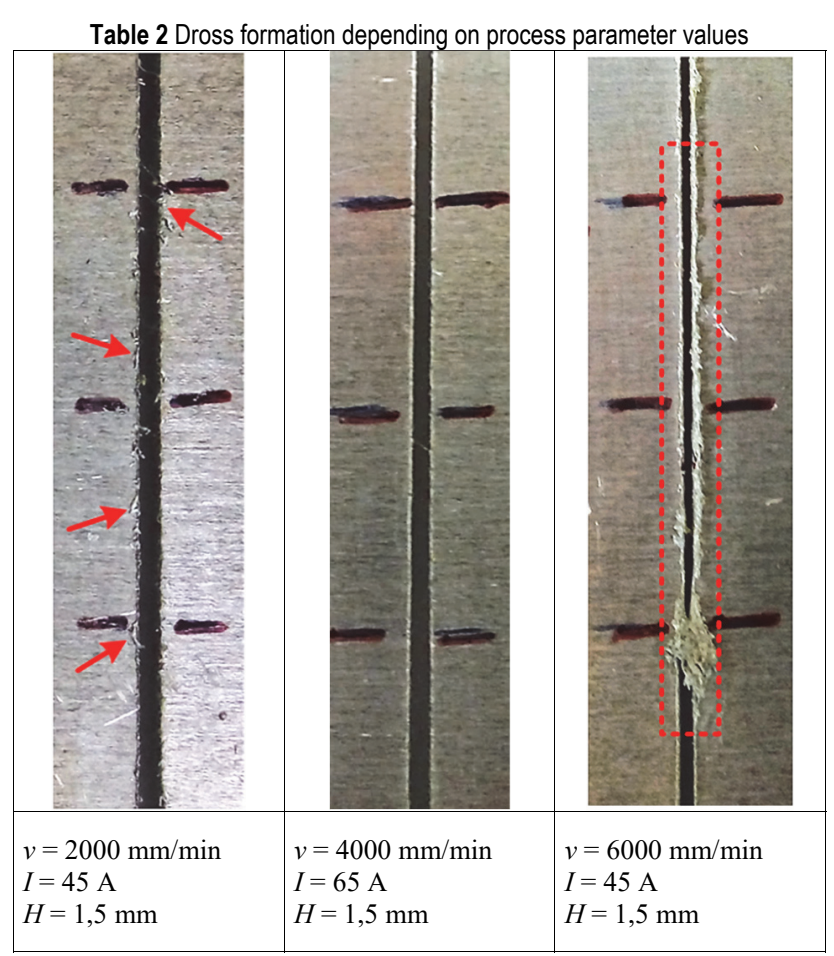




\section{FUZZY LOGIC MODELING}

Fuzzy logic is one of the artificial intelligence methods that is quite useful in describing complex manufacturing processes and systems that consist of ambiguous and imprecise pieces of information and where application of conventional mathematical modelling approaches, such as regression analysis, is not possible. In these cases fuzzy logic represents a good mechanism to create functional relations between analyzed inputs and outputs in order to better understand concrete problem and manufacturing process. The target of this paper is to develop a fuzzy logic model that will predict dross height in plasma jet cutting of aluminium alloy 5083 depending on settings of the process parameters' values. Developed fuzzy logic model needs to have good accuracy so it can be further used in plasma jet cutting process planning and dross height optimization.

Each fuzzy logic system consists of the following components: fuzzification module, fuzzy inference module and defuzzification module [10, 11]. Fuzzification module converts inputs values into linguistic variables using different membership functions. These functions can be: Gaussian, trapezoidal, triangular etc. Membership functions define how each point of inputs and output space is mapped to a membership value between 0 and 1. Fuzzy inference module uses the knowledge base of fuzzy IFTHEN rules and membership functions to create fuzzy linguistic output values. Finally, defuzzification module converts these fuzzy linguistic values into numerical non fuzzy values [11-13].

In this paper, in order to define fuzzy logic model of analyzed plasma jet cutting process response and perform fuzzy reasoning the Mamdani fuzzy inference system was used. Plasma jet cutting process parameters: cutting speed, arc current and cutting height are taken as inputs in fuzzy logic system, while the dross height is considered as output (Fig. 2).

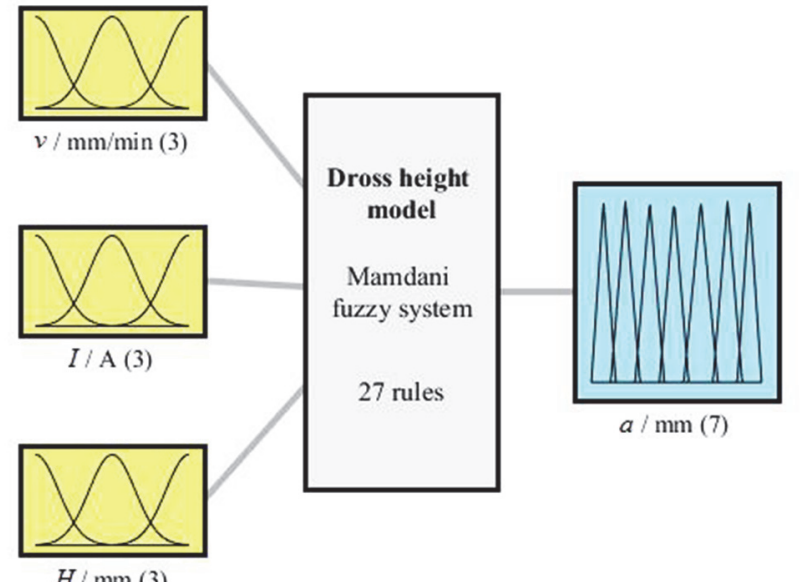

$H / \mathrm{mm}(3)$

Figure 2 Structure of developed fuzzy logic system

For each process parameter three Gaussian membership function were used: low (L), medium (M) and high (H) (Fig. 3a), b) and c)). On the other hand for dross height response seven triangular membership functions were used: very low (VL), low (L), low-medium (LM), medium $(\mathrm{M})$, medium-high $(\mathrm{MH})$, high $(\mathrm{H})$, very high (VH) (Fig. 3d)).

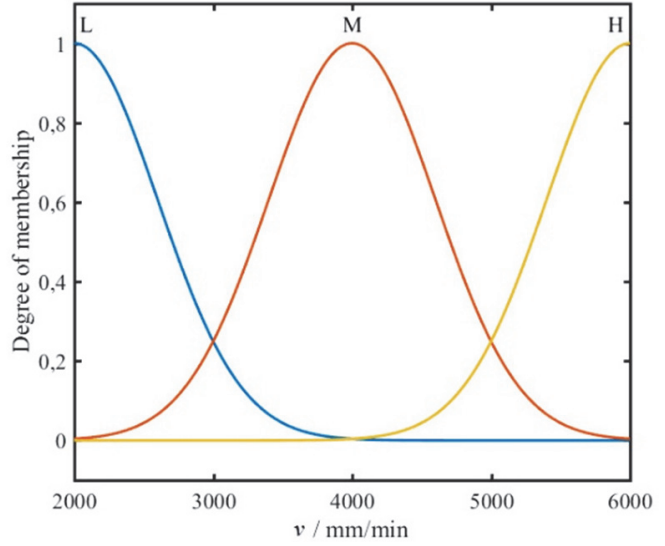

a)

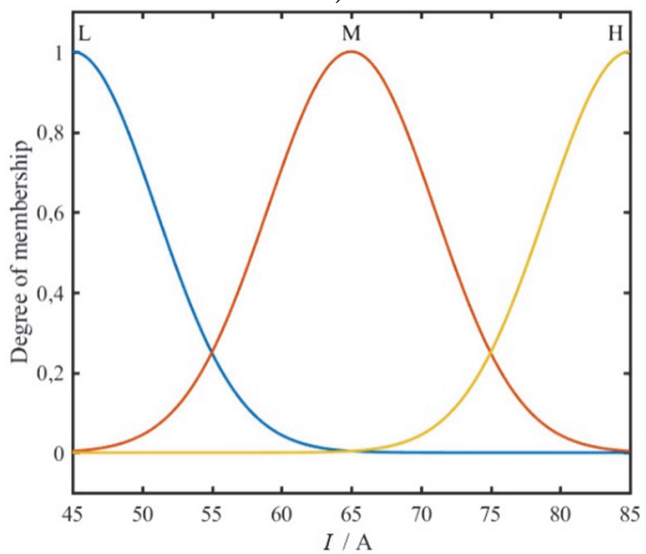

b)

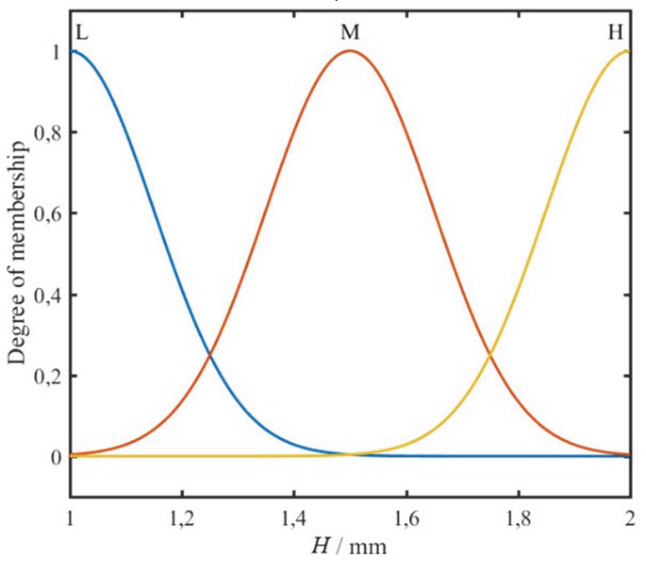

c)

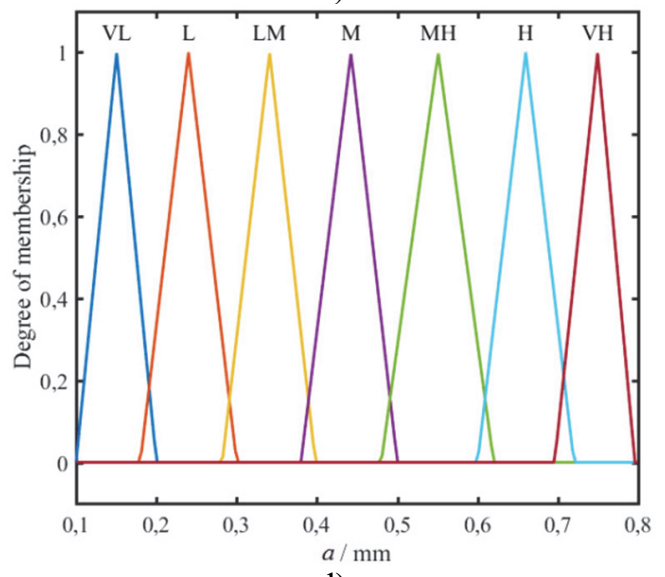

d)

Figure 3 Membership functions for: a) cutting speed, b) arc current, c) cutting height and d) dross height 
In order to define relationship between process parameters and dross height response a set of 27 IF-THEN fuzzy rules was created. These rules are shown in Tab. 3 .
Fuzzy inference system was defined by the following settings: and method: min, or method: max, implication: min, aggregation: max, deffuzification method: centroid.

Table 3 Fuzzy IF-THEN rules
1. If ( $v$ is $\mathrm{L})$ and $(I$ is $\mathrm{L})$ and $(H$ is $\mathrm{L})$ then $(a$ is $\mathrm{L})$
2. If ( $v$ is $\mathrm{L})$ and $(I$ is $\mathrm{L})$ and $(H$ is $\mathrm{M})$ then $(a$ is $\mathrm{L})$
3. If $(v$ is $\mathrm{L})$ and $(I$ is $\mathrm{L})$ and $(H$ is $\mathrm{H})$ then $(a$ is $\mathrm{L})$
4. If $(v$ is $\mathrm{L})$ and $(I$ is $\mathrm{M})$ and $(H$ is $\mathrm{L})$ then $(a$ is $\mathrm{MH})$
5. If $(v$ is $\mathrm{L})$ and $(I$ is $\mathrm{M})$ and $(H$ is $\mathrm{M})$ then $(a$ is $\mathrm{MH})$
6. If $(v$ is $\mathrm{L})$ and $(I$ is $\mathrm{M})$ and $(H$ is $\mathrm{H})$ then $(a$ is $\mathrm{MH})$
7. If ( $v$ is $\mathrm{L})$ and ( $($ is $\mathrm{H})$ and ( $H$ is $\mathrm{L})$ then ( $a$ is LM)
8. If ( $v$ is $\mathrm{L})$ and $(I$ is $\mathrm{H})$ and $(H$ is $\mathrm{M})$ then $(a$ is $\mathrm{M})$
9. If ( $v$ is $\mathrm{L})$ and $(I$ is $\mathrm{H})$ and $(H$ is $\mathrm{H})$ then ( $a$ is LM)
10. If ( $v$ is $\mathrm{M})$ and ( $I$ is $\mathrm{L})$ and $(H$ is $\mathrm{L})$ then ( $a$ is $\mathrm{L})$
11. If ( $v$ is $\mathrm{M})$ and ( $($ is $\mathrm{L})$ and ( $H$ is $\mathrm{M})$ then ( $a$ is $\mathrm{L})$
12. If ( $v$ is $\mathrm{M})$ and $(I$ is $\mathrm{L})$ and $(H$ is $\mathrm{H})$ then $(a$ is $\mathrm{L})$
13. If ( $v$ is $\mathrm{M})$ and $(I$ is $\mathrm{M})$ and $(H$ is $\mathrm{L})$ then ( $a$ is $\mathrm{L})$
14. If ( $v$ is $\mathrm{M})$ and $(I$ is $\mathrm{M})$ and $(H$ is $\mathrm{M})$ then ( $a$ is $\mathrm{VL})$

Deffuzification module from the Matlab R2015 toolbox converts fuzzy values of dross height into numerical non-fuzzy values. In order to check the accuracy of developed fuzzy logic model comparison between original experimental data and fuzzy logic predicted data of dross height was performed. Mean absolute percentage error (MAPE) and coefficient of determination $\left(R^{2}\right)$ were used as comparison measures. MAPE of $8,65 \%$ and $R^{2}$ of 0,97 proved good prediction accuracy of developed fuzzy logic model. These comparison results are shown in Fig. 4.

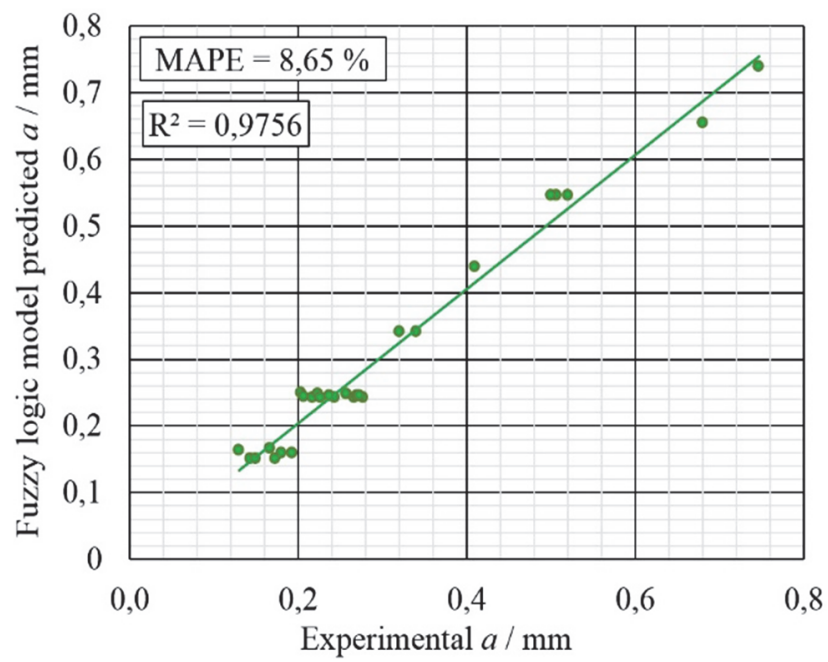

Figure 4 Comparison of dross height experimental and fuzzy logic mode predicted data

In order to check the ability of developed fuzzy logic model to adapt properly on a new unseen data and to prove a repeatability of experiments, a few additional experimental trials were performed according to Taguchi $\mathrm{L}_{9}$ orthogonal array (Tab. 4). New validation of experimentally obtained dross height data was compared with those of fuzzy logic model predicted and previously obtained original experimental data. These results are shown in Fig. 5. Values of MAPE and $R^{2}$ show good generalization ability of developed fuzzy logic model as a repeatability of experiments.
15. If ( $v$ is $\mathrm{M})$ and ( $I$ is $\mathrm{M})$ and $(H$ is $\mathrm{H})$ then ( $a$ is $\mathrm{VL})$

16. If ( $v$ is $\mathrm{M})$ and $(I$ is $\mathrm{H})$ and $(H$ is $\mathrm{L})$ then ( $a$ is VL)

17. If ( $v$ is $\mathrm{M})$ and ( $I$ is $\mathrm{H})$ and $(H$ is $\mathrm{M})$ then ( $a$ is $\mathrm{L})$

18. If ( $v$ is $\mathrm{M})$ and $(I$ is $\mathrm{H})$ and $(H$ is $\mathrm{H})$ then ( $a$ is $\mathrm{VL})$

19. If ( $v$ is $\mathrm{H})$ and ( $I$ is $\mathrm{L})$ and $(H$ is $\mathrm{L})$ then $(a$ is $\mathrm{H})$

20. If $(v$ is $\mathrm{H})$ and $(I$ is $\mathrm{L})$ and $(H$ is $\mathrm{M})$ then $(a$ is $\mathrm{VH})$

21. If ( $v$ is $\mathrm{H})$ and $(I$ is $\mathrm{L})$ and $(H$ is $\mathrm{H})$ then $(a$ is $\mathrm{L})$

22. If ( $v$ is $\mathrm{H})$ and ( $I$ is $\mathrm{M})$ and $(H$ is $\mathrm{L})$ then ( $a$ is $\mathrm{L})$

23. If ( $v$ is $\mathrm{H})$ and ( $I$ is $\mathrm{M})$ and $(H$ is $\mathrm{M})$ then ( $a$ is $\mathrm{L})$

24. If $(v$ is $\mathrm{H})$ and $(I$ is $\mathrm{M})$ and $(H$ is $\mathrm{H})$ then $(a$ is $\mathrm{L})$

25. If $(v$ is $\mathrm{H})$ and $(I$ is $\mathrm{H})$ and $(H$ is $\mathrm{L})$ then ( $a$ is $\mathrm{VL})$

26. If $(v$ is $\mathrm{H})$ and $(I$ is $\mathrm{H})$ and $(H$ is $\mathrm{M})$ then ( $a$ is VL)

27. If ( $v$ is $\mathrm{H})$ and $(I$ is $\mathrm{H})$ and $(H$ is $\mathrm{H})$ then ( $a$ is $\mathrm{VL}$ )

According to that the developed fuzzy logic model can be further used in plasma jet cutting process optimization in order to find out process parameters values that lead to minimal dross height.

Table 4 Validation experiments according to Taguchi L 9 orthogonal array

\begin{tabular}{|c|c|c|c|}
\hline Exp. Trial & $\begin{array}{c}\text { Cutting speed } v / \\
\mathrm{mm} / \mathrm{min}\end{array}$ & $\begin{array}{c}\text { Arc current } I / \\
\text { A }\end{array}$ & $\begin{array}{c}\text { Cutting height } H \\
/ \mathrm{mm}\end{array}$ \\
\hline 1 & 2000 & 45 & 1 \\
\hline 2 & 2000 & 65 & 1,5 \\
\hline 3 & 2000 & 85 & 2 \\
\hline 4 & 4000 & 45 & 1,5 \\
\hline 5 & 4000 & 65 & 2 \\
\hline 6 & 4000 & 85 & 2 \\
\hline 7 & 6000 & 45 & 1 \\
\hline 8 & 6000 & 65 & 1,5 \\
\hline 9 & 6000 & 85 & 1 \\
\hline
\end{tabular}

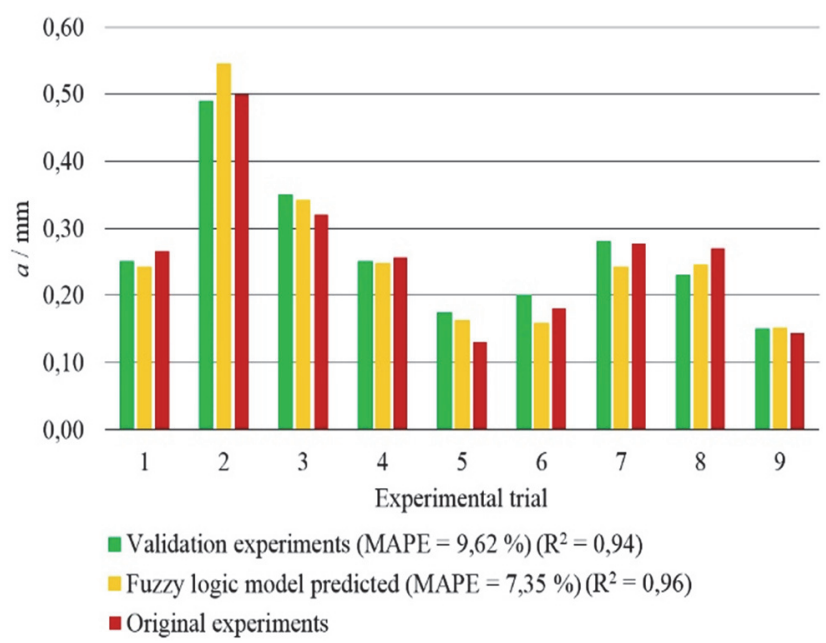

Figure $\mathbf{5}$ Dross height validation experimental data compared with original experimental data and fuzzy logic model predicted data 


\section{RESULTS}

After fuzzy logic model was created and validated it can be further used for analysis of the process parameters effects on dross height response. In order to perform that,
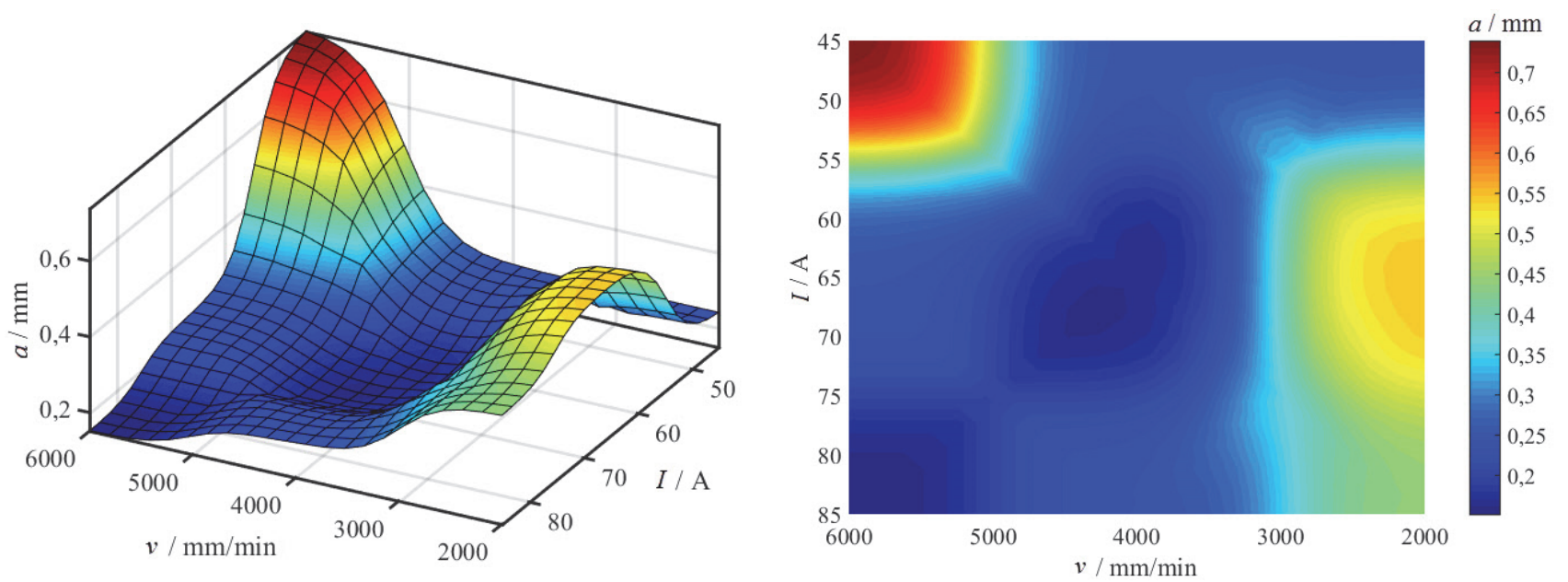

a)
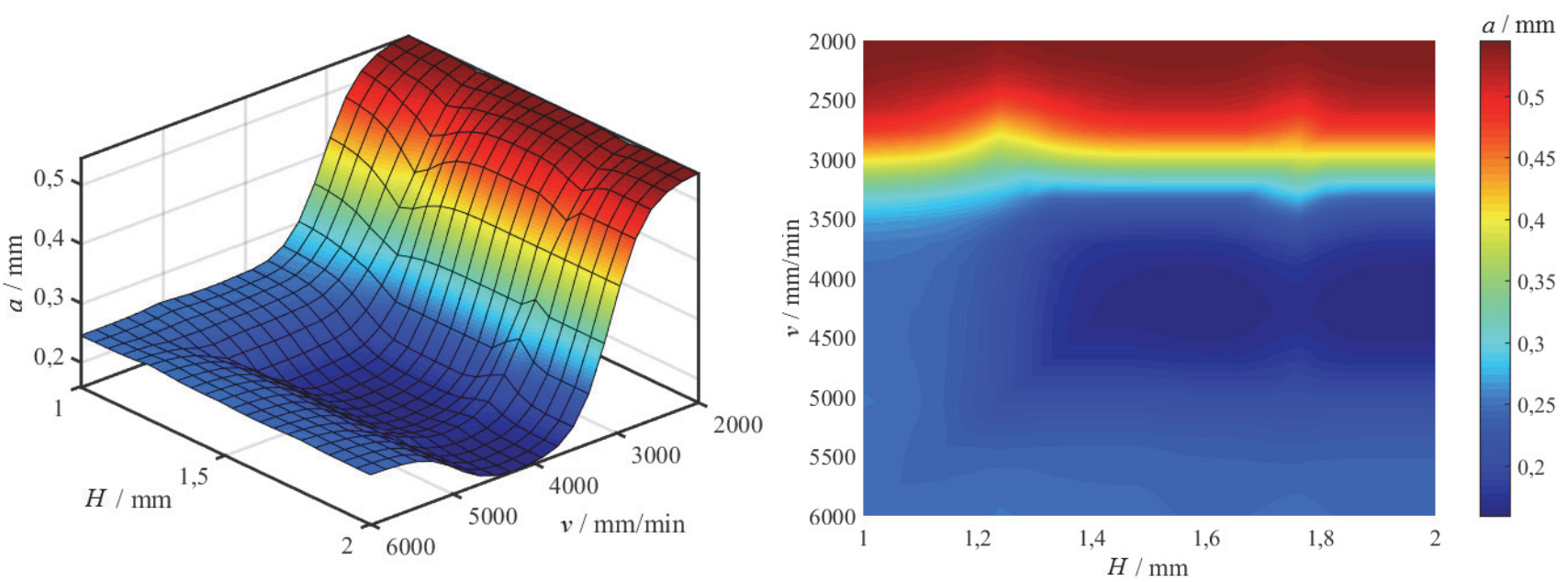

b)
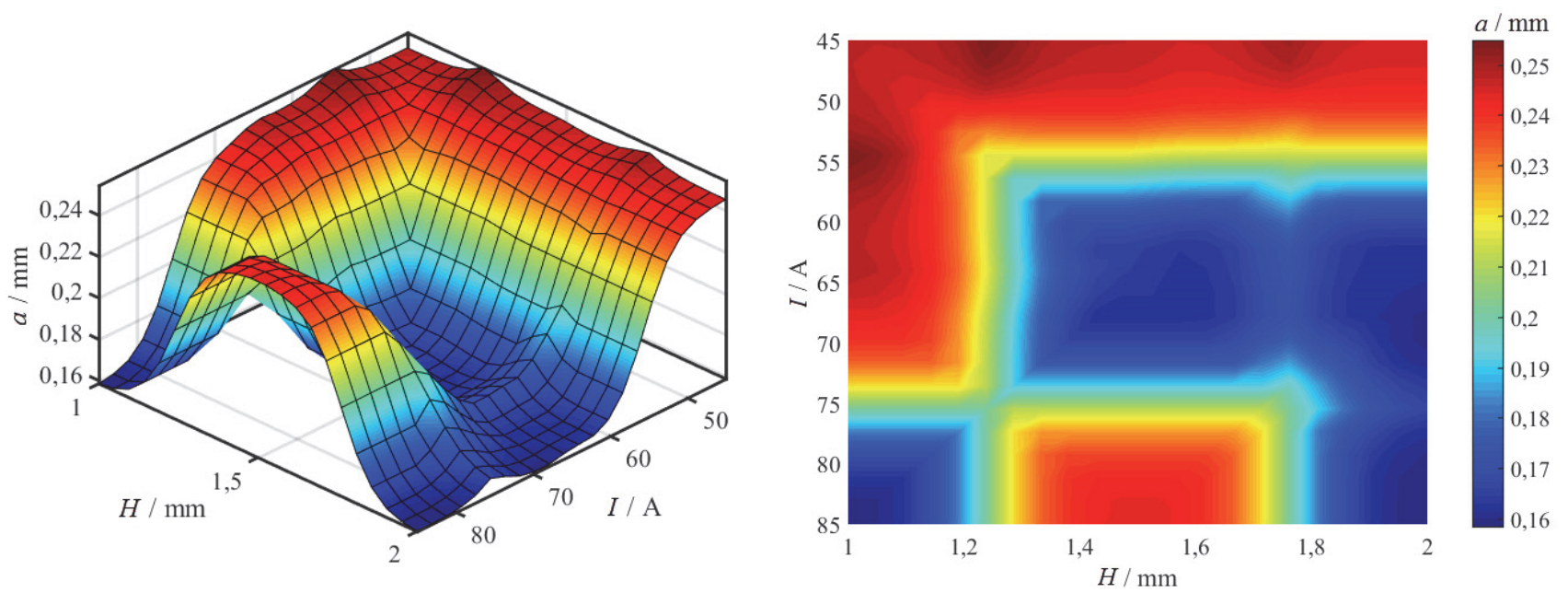

c)

Figure 6 Interaction effects of plasma jet cutting process parameters on the dross height: a) cutting height $=1.5 \mathrm{~mm}, \mathrm{~b}$ ) arc current $=65 \mathrm{~A}, \mathrm{c})$ cutting speed $=4000$ $\mathrm{mm} / \mathrm{min}$ 
From Fig. 6 it is obvious that process parameters differently affect the dross formation in the plasma jet cutting of aluminium alloy 5083. Also, generated 3D surface and contour plots indicate that there is also an optimal cutting area where the dross height is minimal. Fig. 6 a shows that the highest dross height is obtained by cutting speed of $6000 \mathrm{~mm} / \mathrm{min}$ and arc current of $45 \mathrm{~A}$. The main explanation for that appearance is a strong disturbance of the molten material flow by high cutting speeds and low arc currents. Also, high dross formation is visible by very low cutting speeds $(2000 \mathrm{~mm} / \mathrm{min})$ and high arc currents (65 - $85 \mathrm{~A}$ ) because of higher energy input. That statement is confirmed also by Fig. 6b. From that figure it can be observed that the highest dross height appears at the lowest cutting speed $(2000 \mathrm{~mm} / \mathrm{min})$ and higher arc current $(65 \mathrm{~A})$. Also, it is visible that cutting height does not have a noticeable influence on the dross formation by the arc current of $65 \mathrm{~A}$. Fig. $6 \mathrm{c}$ indicates that by cutting speed of $4000 \mathrm{~mm} / \mathrm{min}$ and arc current of $45 \mathrm{~A}$ the dross is visible, but not so high. The explanations for that have already been defined: pronounced instability of plasma jet and disturbance of molten material flow. Cutting height does not have an impact on the analyzed response in this area. Regarding cutting height in the area of cutting speed of $4000 \mathrm{~mm} / \mathrm{min}$ and arc currents of $65-85 \mathrm{~A}$, the desirable values that lead to low dross height are those higher than $1,5 \mathrm{~mm}$. Finally, the optimal cutting areas of process parameters, where dross formation is minimal, can be defined as cutting speed: $4000 \mathrm{~mm} / \mathrm{min}$, arc current: 65 A, cutting height: $1,5-2 \mathrm{~mm}$ and cutting speed: 6000 $\mathrm{mm} / \mathrm{min}$, arc current: $85 \mathrm{~A}$, cutting height: $1,5-2 \mathrm{~mm}$. After definition of optimal cutting area in order to confirm these findings, a few experimental trials were performed by optimal process parameters values. Some of them are shown in Tab. 5.

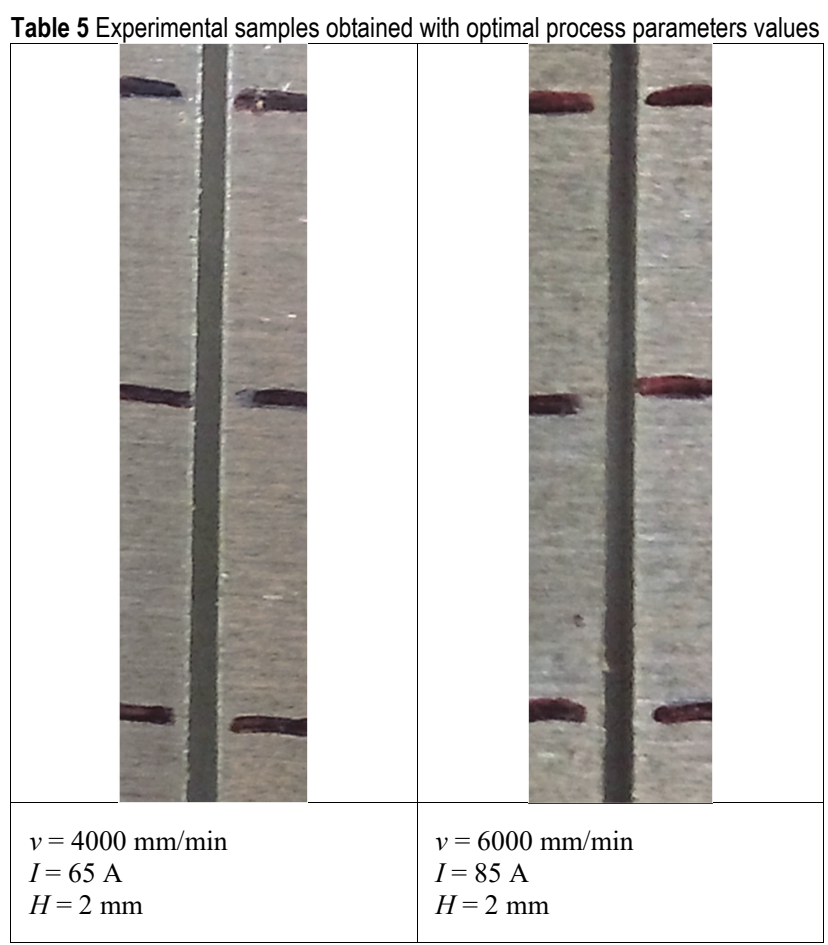

\section{CONCLUSION}

In this paper a Mamdani fuzzy logic model was developed to predict dross formation depending on process parameters such as cutting speed, arc current and cutting height in plasma jet cutting process of aluminium alloy 5083. From the defined fuzzy logic model and within experimental hyperspace it can be concluded that:

- Process parameters and their interactions differently and significantly affect dross formation.

- Influence of each process parameter on dross height should be considered through interactions with other process parameters.

- Cutting speed has the most significant effect on dross formation followed by arc current and cutting height.

- Optimal cutting areas where dross height is minimal can be successfully defined within the analyzed experimental hyperspace.

- Optimal cutting areas are: cutting speed: 4000 $\mathrm{mm} / \mathrm{min}$; arc current: $65 \mathrm{~A}$; cutting height: 1,5 - $2 \mathrm{~mm}$ and cutting speed: $6000 \mathrm{~mm} / \mathrm{min}$, arc current: $85 \mathrm{~A}$, cutting height: $1,5-2 \mathrm{~mm}$.

- Artificial intelligence technique: fuzzy logic is very useful in describing complex manufacturing processes that consist of imprecisions and where application of conventional mathematical modelling approaches is not convenient. One of these processes is surely the plasma jet cutting process of aluminium alloy.

- Mamdani fuzzy inference system combined with Gaussian and triangular membership functions and centroid defuzzification method represent good settings for dross height modelling.

- Findings obtained in this research can assist technologists and process engineers in better plasma jet cutting process planning and further technology and cut quality characteristics improvements.

\section{REFERENCES}

[1] Peko, I., Nedić, B., Đorđević, A., \& Veža, I. (2018). Modelling of Kerf Width in Plasma Jet Metal Cutting Process using ANN Approach. Technical Gazette, 25(2), 401-406. https://doi.org/10.17559/TV-20161024093323

[2] Kumar Das, M., Kumar, K., Barman, K. T., \& Sahu, P. (2014). Optimization of process parameters in plasma arc cutting of EN31 steel based on MRR and multiple roughness characteristics using grey relational analysis. Procedia material science, $5,1550-1559$.

https://doi.org/10.1016/j.mspro.2014.07.342

[3] Adalarasan, R., Santhanakumar, M., \& Rajmohan, M. (2015). Application of Grey Taguchi-based response surface methodology (GT-RSM) for optimizing the plasma arc cutting parameters of $304 \mathrm{~L}$ stainless steel. International Journal of Advanced Manufacturing Technology, 78, 11611170. https://doi.org/10.1007/s00170-014-6744-0

[4] Tsiolikas, A., Kechagias, J., Salonitis, K. \& Mastorakis, N. (2016). Optimization of cut surface quality during CNC Plasma Arc Cutting process. International Journal of Systems Applications, Engineering \& Development, 10, 305-308. Retrieved from http://www.naun.org/cms.action?id=12108

[5] Maity, K. P. \& Kumar Bagal, D. (2015). Effect of process parameters on cut quality of stainless steel of plasma arc cutting using hybrid approach. International Journal of Advanced Manufacturing Technology, 78, 161-175. https://doi.org/10.1007/s00170-014-6552-6 
[6] Radovanovic, M. \& Madic, M. (2011). Modeling the plasma arc cutting process using ANN. Nonconventional Technologies Review, 4, 43-48.

[7] Srinivasa Raju, S. V. S. S., Kodanda Ram, K., Satyanarayana, D. V. S. S., \& Sai NishoodGoud, M. (2016). Optimization of Process Parameters of Plasma Arc Cutting Using Taguchi's Robust Design Methodology. IOSR Journal of Mechanical and Civil Engineering,International Conference on Recent Innovations in Civil \& Mechanical Engineering, 3, 124-128. https://doi.org/10.9790/1684-1605303124128

[8] Pawar, S.S. \&Inamdar, K.H. (2017). Experimental Analysis of Plasma Arc Cutting Process for SS 316L Plates. IOSR Journal Of Mechanical and Civil Engineering, 6th National Conference on "Recent Developments In Mechanical Engineering", 5, 75-80. https://doi.org/10.9790/1684-17010057580

[9] Salonitis, K. \& Vatousianos, S. (2012). Experimental investigation of the plasma arc cutting process. Procedia CIRP, 3, 287-292.

https://doi.org/10.1016/j.procir.2012.07.050

[10] Dragičević, M., Begović, E., \& Peko I. (2019). Multiobjective optimization of MQLC turning process parameters using grey-fuzzy approach. Journal of Mechanical Engineering, 16(1-2), 3-13. Retrieved from http://mf.unze.ba/wp-content/uploads/2019/06/DragicevicBegovic.pdf

[11] Dragičević, M., Begović, E., \& Peko I. (2019). Optimization of dry turning process parameters using Taguchi method combined with fuzzy logic approach. $16^{\text {th }}$ International Conference on Tribology / Kragujevac, Serbia, 429-435.

[12] Madić, M., Ćojbašić, Ž., \& Radovanović, M. (2016) Comparison of fuzzy logic, regression and ANN laser kerf width models. UPB Scientific Bulletin, Series D: Mechanical Engineering, 78(1), 197-212. Retrieved from https://www.scientificbulletin.upb.ro/rev_docs_arhiva/full3 3e_403937.pdf

[13] Madić, M., Radovanović, M., Ćojbašić, Ž., Nedić, B. \& Gostimirović, M. (2015). Fuzzy Logic Approach for the Prediction of Dross Formation in $\mathrm{CO}_{2}$ Laser Cutting of Mild Steel. Journal of Engineering Science and Technology Review, 8(3), 143-150. https://doi.org/10.25103/jestr.083.19

\section{Contact information:}

Ivan PEKO, PhD, Development Engineer

(Corresponding author)

AD Plastik Group,

Matoševa 8, 21210, Solin, Croatia

E-mail: ipeko@fesb.hr

Bogdan NEDIĆ, PhD, Full Professor

Faculty of Engineering, University of Kragujevac,

Sestre Janjić 6, 34000 Kragujevac, Serbia

E-mail: nedic@kg.ac.rs

Marko DUNĐER, PhD, Full Professor

Study of Polytechnic, University of Rijeka,

Sveučilišna avenija 4, 51000 Rijeka, Croatia

E-mail: marko.dundjer1@gmail.com

Ivan SAMARDŽIĆ, PhD, Full Professor

Mechanical Engineering Faculty in Slavonski Brod,

Sveučilište u Slavonskom Brodu

Trg Stjepana Miletića 12, 35000 Slavonski Brod, Croatia

E-mail: isamar@sfsb.hr 